\title{
Evidence of a weakly absorbing intermediate mode of aerosols in AERONET data from Saharan and Sahelian sites
}

\author{
Scott M. Gianelli, ${ }^{1,2,3}$ Andrew A. Lacis, ${ }^{4}$ Barbara E. Carlson, ${ }^{4}$ and Sultan Hameed ${ }^{1}$ \\ Received 9 June 2013; revised 24 October 2013; accepted 27 October 2013; published 19 November 2013.
}

[1] Accurate retrievals of aerosol size distribution are necessary to estimate aerosols' impact on climate and human health. The inversions of the Aerosol Robotic Network (AERONET) usually retrieve bimodal distributions. However, when the inversion is applied to Saharan and Sahelian dust, an additional mode of intermediate size between the coarse and fine modes is sometimes seen. This mode explains peculiarities in the behavior of the Ångström exponent, along with the fine mode fraction retrieved using the spectral deconvolution algorithm, observed in a March 2006 dust storm. For this study, 15 AERONET sites in northern Africa and on the Atlantic are examined to determine the frequency and properties of the intermediate mode. The mode is observed most frequently at Ilorin in Nigeria. It is also observed at Capo Verde and multiple sites located within the Sahel but much less frequently at sites in the northern Sahara and the Canary Islands. The presence of the intermediate mode coincides with increases in Ångström exponent, fine mode fraction, single-scattering albedo, and to a lesser extent percent sphericity. The Ångström exponent decreases with increasing optical depth at most sites when the intermediate mode is present, but the fine mode fraction does not. Single-scattering albedo does not steadily decrease with fine mode fraction when the intermediate mode is present, as it does in typical mixtures of dust and biomass-burning aerosols. Continued investigation is needed to further define the intermediate mode's properties, determine why it differs from most Saharan dust, and identify its climate and health effects.

Citation: Gianelli, S. M., A. A. Lacis, B. E. Carlson, and S. Hameed (2013), Evidence of a weakly absorbing intermediate mode of aerosols in AERONET data from Saharan and Sahelian sites, J. Geophys. Res. Atmos., 118, 12,661-12,672, doi:10.1002/2013JD020342.

\section{Introduction}

[2] One of the hardest physical attributes of aerosols to quantify is the size distribution. Particles in the air can have a broad range of sizes, and often aerosols in a given parcel of air can be grouped into two or more discrete size categories or modes. In a bimodal distribution, for example, the mode of larger particles (typically of a radius greater than $1 \mu \mathrm{m})$ is called the coarse mode and the mode of smaller particles (typically of a radius less than $1 \mu \mathrm{m}$ ) is called the fine mode.

[3] Understanding the details of the size distribution facilitates the simulation of particle transport and improves

\footnotetext{
${ }^{1}$ School of Marine and Atmospheric Sciences, Stony Brook University, Stony Brook, New York, USA.

${ }^{2}$ Department of Physical Sciences, St. Joseph's College, Patchogue, New York, USA.

${ }^{3}$ Department of Physics and Astronomy, Hofstra University, Hempstead, New York, USA. USA.

${ }^{4}$ NASA Goddard Institute for Space Studies, New York, New York,

Corresponding author: S. M. Gianelli, School of Marine and Atmospheric Sciences, Stony Brook University, Stony Brook, NY 11790, USA. (sgianell@yahoo.com)

C2013. American Geophysical Union. All Rights Reserved. 2169-897X/13/10.1002/2013JD020342
}

scientific understanding of the indirect effect that aerosols exert on clouds and the effect of aerosols on human health. A recent study by Ridley et al. [2012] has shown that correctly proportioning the contributions of submicron particles to the total dust aerosol mass improves agreement between model simulations and observations of aerosol optical depth from Saharan dust events that cross the Atlantic. The cloud nucleating ability of aerosol particles has been shown by Dusek et al. [2006] to depend more on the aerosol size distribution than on aerosol chemistry, and Romakkaniemi et al. [2012] have observed that changes in the aerosol size distribution can offset the influence that changes in optical depth have on cloud properties.

[4] The effect that aerosols have on human health is the subject of much speculation and study. Studies such as Cohen et al. [2005] and Anenberg et al. [2010], for example, estimate that particles with a diameter less than $2.5 \mu \mathrm{m}$ $\left(\mathrm{PM}_{2.5}\right)$ cause significant loss of life each year, but they differ on the specific numbers. The Sahara Desert and the Sahel region directly south of the Sahara inject massive amounts of dust aerosols into the atmosphere. West Africa has high mortality rates for respiratory infections, but the degree of research into the effects of Saharan and Sahelian dust on these mortality rates has been insufficient to date $[D e$ Longueville et al., 2010]. Recent research has, however, implicated desert dust in outbreaks of meningitis in the 
Sahel [Martiny and Chiapello, 2013]. Satellite-derived estimates of aerosol amounts can serve as an adequate proxy measurement for surface levels of $\mathrm{PM}_{10}$ or particles with a diameter of $10 \mu \mathrm{m}$ or less [Deroubaix et al., 2013]; in principle, this should help to more clearly define the connection between dust particles and meningitis. It is not yet clear, though, how significant the details of the size distribution of desert dust aerosols are to their impact on the human health issues observed in the western part of Africa.

[5] Some general information about the aerosol size distribution may be inferred from radiometric data, since changes in particle size lead to changes in the wavelength dependence of the atmospheric extinction or optical depth. Hansen and Travis [1974] used Mie scattering theory to demonstrate that the extinction due to scattering of a given particle decreases with increasing wavelength, provided that the particle radius does not exceed the wavelength of the light. Many subsequent studies have built on this result to develop algorithms that retrieve general information about the aerosol size distribution. Kassianov et al. [2005], for example, devised an algorithm that was then employed by Slingo et al. [2006] to calculate the effective radius of Saharan dust particles using direct beam radiometric data from a Mutifilter Rotating Shadowband Radiometer (MFRSR) [Harrison et al., 1994] instrument sited in Niamey, Niger.

[6] One way that scientists have used to determine more specific information about the aerosol size distribution is to calculate the Ångström exponent $(\alpha)$, a measure of the wavelength dependence of aerosol extinction. It is defined relative to two wavelengths and obtained from the formula $\tau_{1}=\tau_{0}$ * $\left(\lambda_{1} / \lambda_{0}\right)^{-\alpha}$, where $\tau_{0}$ and $\tau_{1}$ are the aerosol optical depths measured at the wavelengths $\lambda_{0}$ and $\lambda_{1}$. Larger particles, like desert dust, have smaller Ångström exponents. Values of $\alpha$ measured in Saharan dust storms between 500 and $875 \mathrm{~nm}$ typically range from 0 (i.e., no discernible change in aerosol optical depth with wavelength) to 0.25 [Holben et al., 1991]. By contrast, smaller particles like biomass-burning aerosols can have an Ångström exponent in excess of 2.0 between 500 and $875 \mathrm{~nm}$ [Kaufman et al., 1992].

[7] A typical air mass can contain multiple types of aerosols in multiple size modes, so the wavelength dependence of the optical depth due to each mode needs to be taken into account when evaluating the size distribution in more detail. Schuster et al. [2006] demonstrated that the Ångström exponent, when measured relative to different combinations of wavelengths, can provide information on different aspects of the size distribution. When $\alpha$ is derived from long wavelengths, like $675 \mathrm{~nm}$ and $870 \mathrm{~nm}$ for example, it provides information on the relative concentrations of particles in different size modes. And when it is derived from shorter wavelengths, it provides information on the size of the particles within the fine aerosol mode.

[8] The principal source of ground-based measurements of aerosol optical depth and retrievals of size distributions is the Aerosol Robotic Network or AERONET [Holben et al., 1998]. AERONET has instruments on every continent and several remote island locations. The measuring instrument employed by AERONET is the CIMEL CE-318 automatic sun-tracking photometer. This device measures the intensity of the direct solar beam as the sun moves across the sky, from which the aerosol optical depth at seven wavelengths between 340 and $1020 \mathrm{~nm}$ is calculated. Eck et al. [1999] estimated uncertainties in AERONET optical depth measurements to be $\sim 0.01$ at longer wavelengths and 0.02 at shorter wavelengths. The primary source of error comes from calibration errors, but errors in the calculation of optical depth due to Rayleigh scattering and ozone play a role as well.

[9] Periodically during the day, the CIMEL instrument measures scattered radiation at multiple angles, either through an almucantar or a solar principal plane. Dubovik and King [2000] devised a retrieval algorithm for AERONET which combines the direct sun and scattered radiance measurements at wavelengths of $440,675,870$, and $1020 \mathrm{~nm}$ to retrieve the full aerosol size distribution. The algorithm also retrieves one value of the real and imaginary index of refraction and the single-scattering albedo (the ratio of scattering optical depth to total optical depth) at each of the corresponding wavelengths. The retrieved size distribution is expressed as the change in total aerosol volume with respect to the change in the logarithm of the particle radius, $\mathrm{d} V / \mathrm{d}(\ln r)$, over 22 different size bins ranging from $0.05 \mu \mathrm{m}$ to $15.0 \mu \mathrm{m}$. Dubovik and King [2000] estimated the uncertainty in $\mathrm{d} V / \mathrm{d}(\ln r)$ due to random errors to be less than $5 \%$ for nearly all particle sizes except the extreme ones, for which the retrieved total volume is usually very small. The original version of the algorithm assumed all the particles were spherical, however. To correct for errors that occurred when the aerosols being observed were non-spherical dust particles, Dubovik et al. [2006] developed a new algorithm, called Version 2.0 that incorporates spheroidal-shaped particles in addition to spherical particles.

[10] There have been a limited number of opportunities to validate the AERONET inversion with direct measurements of aerosol size distributions. Osborne et al. [2008] and Johnson and Osborne [2011] have compared airborne measurements of size distributions with AERONET retrievals of Saharan and Sahelian dust. Both these studies showed generally good qualitative agreement between the AERONET Version 2.0 algorithm and airborne measurements, but there are some differences. In the Osborne et al. study, the AERONET algorithm produced higher concentrations of submicron particles than were measured on the airplane, while airborne measurements of the Johnson and Osborne study showed a dominant coarse mode of slightly smaller-sized particles and a slightly narrower variance compared to AERONET. The Ångström coefficients measured by Osborne et al. were significantly lower than those measured by AERONET, though, so the airborne samples may not have been fully representative of the entire atmospheric column.

[11] O'Neill et al. [2003] devised the spectral deconvolution algorithm (SDA) to analyze bimodal aerosol size distributions using only AERONET optical depth data. The algorithm makes the assumption that the size distribution consists of one fine mode and one coarse mode, where the coarse mode extinction is essentially constant with wavelength (its Ångström exponent and first derivative are both constrained to be close to zero). The aerosol extinction at $500 \mathrm{~nm}$ is then retrieved for both modes. The Dubovik et al. [2006] inversion also can be used to calculate basic properties, like the effective radius and variance, for the coarse and fine modes. It is important to note, though, that the two algorithms define the coarse and fine modes differently. The Dubovik et al. inversion separates the coarse and fine modes at the radius between $0.439 \mu \mathrm{m}$ and $0.992 \mu \mathrm{m}$ for which is retrieved the minimum value of $\mathrm{d} V / \mathrm{d}$ 
Table 1. A List of the Sites Used in This Study Along With Their Locations and Years of Available Data

\begin{tabular}{lccccc}
\hline Site & Latitude & Longitude & Elevation & Country & Years \\
\hline Agoufou & 15.345 & -1.479 & 305 & Mali & $2003-2009$ \\
Banizoumbou & 13.541 & 2.665 & 250 & Niger & $1995-1997,1999-2011$ \\
Blida & 36.508 & 2.881 & 230 & Algeria & $2003-2010,2012$ \\
Capo Verde & 16.733 & -22.935 & 60 & Cape Verde & $1996-1997,1999-2012$ \\
Dakar & 14.394 & -16.959 & 0 & Senegal & $1996-1997,2000-2001,2003-2012$ \\
DMN Maine Soroa & 13.217 & 12.023 & 350 & Niger & $2005-2010$ \\
IER Cinzana & 13.278 & -5.934 & 285 & Mali & $2004-2012$ \\
Ilorin & 8.320 & 4.340 & 350 & Nigeria & $1998-2002,2005-2012$ \\
Izana & 28.309 & -16.499 & 2391 & Canary Islands & $2004-2012$ \\
La Laguna & 28.482 & -16.321 & 568 & Canary Islands & $2009-2012$ \\
Ouagadougou & 12.200 & -1.400 & 290 & Burkina Faso & $1999-2007$ \\
Saada & 31.626 & -8.156 & 420 & Morocco & $2004-2012$ \\
Santa Cruz Tenerife & 28.473 & -16.247 & 52 & Canary Islands & $2005-2011$ \\
Tamanrasset INM & 22.790 & 5.530 & 1377 & Algeria & $2006-2009$ \\
Zinder Airport & 13.777 & 8.990 & 456 & Niger & $2009-2012$ \\
\hline
\end{tabular}

(ln $r$ ). By contrast, the O'Neill et al. algorithm separates the modes in a way that does not directly refer to specific particle sizes. It instead treats the curve of total aerosol optical depth versus wavelength as the sum of two distinct curves, of which the fine mode curve decreases more steadily with wavelength and the coarse mode curve varies only slightly with wavelength. The extinction curves of the two modes are constrained based on a statistical analysis of actual data [O'Neill et al., 2001].

[12] The low values of the Ångström exponent calculated from optical depth measurements of dust from the Sahara and Sahel indicate that the dust is dominated by larger, coarse mode particles. At least one study [Gomes et al., 1990] has suggested, though, that strong enough winds in the Sahara can produce an additional mode of submicron dust particles. Gomes et al. concluded that the likely cause of this submicron mode is sandblasting. Reid et al. [2008] looked for evidence of this additional mode and found nothing conclusive, but their study took place in the United Arab Emirates, not in the Sahara or the Sahel. Todd et al. [2007], on the other hand, observed a distinct size mode with a peak in aerosol volume at approximately $0.5 \mu \mathrm{m}$ in AERONET size distribution retrievals from the Bodélé Depression in Chad during the BoDEx 2005 experiment. They also reported that some in situ dust samples showed similar results to the AERONET retrievals. Eck et al. [2010] also observed this intermediatesized mode in AERONET retrievals from the site at Ilorin, in the African nation of Nigeria, and identified the Bódélé Depression as a possible source because of the consistency between their observations and those of Todd et al.

[13] If there is indeed an intermediate mode present at least some of the time in Saharan and Sahelian dust events, some understanding of the dynamical processes is necessary to determine if the Bodélé Depression or some place else is the likely source of these particles. For example, the analysis of satellite data done by Schepanski et al. [2012] indicates that the Bodélé Depression is the strongest individual source of dust in the world, but plenty of other regions of the Sahara and the Sahel (both to the east and west of the Bodélé Depression) produce significant amounts of dust as well. Furthermore, Fiedler et al. [2013] show that the nocturnal low-level jets that lift dust out of the Bodélé Depression in the dusty season from November to March come from the northeast $68 \%$ of the time and from the east less than $20 \%$ of the time. A jet from the northeast would blow the Bodélé dust southwest toward Nigeria (and the AERONET site at Ilorin), while a jet from the east would blow the dust westward across the Sahel.

[14] This study shows that an intermediate mode has been retrieved in AERONET inversions of Saharan and Sahelian dust at multiple sites often enough to establish some general characteristics. In particular, there are statistically significant differences in the Ångström exponent, fine mode fraction, and the single-scattering albedo when this mode is observed in the data. Section 2 lists the AERONET sites used in this study, explains the methodology used to identify the data points in which the intermediate mode is significantly present, and describes the statistical analysis performed on the data. In section 3 , it is shown that the intermediate mode can explain some peculiarities in the radiative properties of a well-documented Saharan dust storm that took place in March 2006 [Derimian et al., 2008; Skonieczny et al., 2011; Slingo et al., 2006; Thomas and Gautier, 2009]. Section 4 contains the main body of work. The frequencies with which the intermediate mode is flagged in the AERONET retrievals are presented for 15 sites, and the degree to which frequency varies with optical depth is investigated. For the 10 sites at which the frequency of occurrence of the intermediate mode is shown to be significant, differences between the Ångström exponent, fine mode fraction, single-scattering albedo, and percent sphericity between the data points in which the intermediate mode is and is not observed are examined as well. A discussion of why the authors believe the intermediate mode reflects physical reality and is not an artifact of the AERONET inversion and how to proceed with further investigation of the intermediate mode is presented in section 5. Section 6 contains the summary and concluding remarks.

\section{Data and Methods}

[15] Table 1 presents a list of the 15 AERONET sites used in this study. The sites cover the northern (Blida and Saada) and central (Tamanrasset INM) Sahara; a belt of Sahelian sites stretching from Niger westward to the Atlantic Ocean (Zinder Airport, DMN Maine Soroa, Banizoumbou, Agoufou, Ouagadougou, IER Cinzana, and Dakar); island sites in the Atlantic influenced by Saharan and Sahelian dust (Izana, La Laguna, and Santa Cruz Tenerife in the Canary Islands, plus Capo Verde on Sal Island in Cape Verde); and 


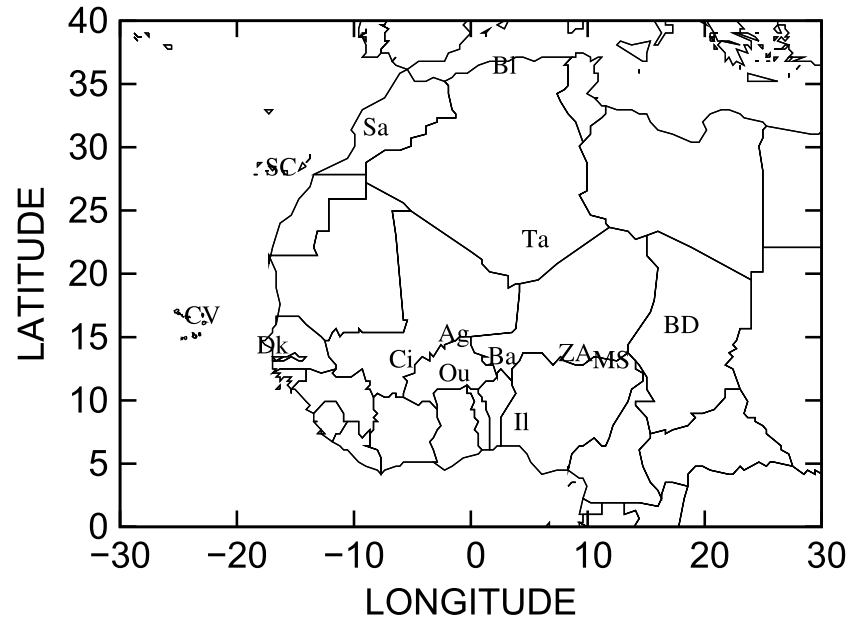

Figure 1. A map of northern Africa and the adjacent portion of the Atlantic Ocean. The locations of the AERONET sites at Agoufou (Ag), Banizoumbou (Ba), Blida (Bl), Capo Verde (CV), Dakar (D), DMN Maine Soroa (MS), IER Cinzana (CI), Ilorin (II), Ouagadougou (Ou), Saada (Sa), Santa Cruz Tenerife (SC), Tamanrasset (Ta), and Zinder Airport (ZA) are identified, along with the location of the Bodélé Depression (BD). Two additional Canary Islands sites (Izana and La Laguna), located at different elevations than Santa Cruz Tenerife but at a similar latitude and longitude, are included in the study as well.

the site at Ilorin in Nigeria, which is frequently downwind of dust storms emanating from the Bodélé Depression [Eck et al., 2010]. The table also lists the years for which data were obtained for each site, along with the versions of qualityscreened data used. Level 2.0 quality-screened data were used for both the optical depth data and the size distribution inversions at all sites. Level 2.0 SDA retrievals were used at Blida, Ilorin, Izana, La Laguna, Santa Cruz Tenerife, and Tamanrasset INM. The remaining sites use Level 1.5 SDA retrievals due to a shortage or lack of available Level 2.0 retrievals at those locations. This allows for the SDA retrieval results to be examined at all the sites, but the chance of systematic errors in the retrievals due to calibration and instrumentation issues and fewer data quality checks is greater in the Level 1.5 screening.

[16] A map of the northern part of Africa, with letters indicating the locations pertinent to this study, is presented in Figure 1. The Dubovik et al. [2006] Version 2.0 algorithm, which assumes a combination of spherical- and spheroidalshaped particles in order to better simulate desert dust optical properties, retrieves size distribution, single-scattering albedo, and percent sphericity. The bimodal size distribution retrievals from the SDA are used as well. The SDA values are taken from the closest data point in time to the results of the size distribution inversion, provided that the time difference is less than $1 \mathrm{~h}$.

[17] In order to examine the properties of the intermediate mode, it is first necessary to devise an objective means of determining when it makes a significant contribution to the total aerosol loading. For the sake of simplicity, a given size distribution inversion is said to show a significant presence of the intermediate mode if the Dubovik et al. [2006] inversion retrieves two distinct peaks in $\mathrm{d} V / \mathrm{d}(\ln r)$ at radii corresponding to what the AERONET algorithm defines as the coarse mode, but at least one of these peaks is retrieved at a submicron radius. To illustrate this, Figure 2 shows the daily mean value for the size distribution retrievals at Ilorin during a dust event on 10 February 2000, for which the mean optical depth at $870 \mathrm{~nm}$ is 1.67 and the Ångström exponent between $440 \mathrm{~nm}$ and $870 \mathrm{~nm}$ is 0.336 . The first vertical dashed line on Figure 2, corresponding to a particle radius of $0.439 \mu \mathrm{m}$, denotes where the AERONET inversion divides the total aerosol loading into coarse and fine modes. The second dashed line at $0.992 \mu \mathrm{m}$ is the cutoff above which a peak will not be flagged as representing the intermediate mode. The retrieved size distribution on this particular day shows three distinct modes: a fine mode most likely due to biomass burning, a large coarse mode typically seen in size distributions of desert dust, and a clear intermediate mode that peaks squarely within the defined size range.

[18] This methodology is admittedly inexact, and care must be taken to avoid confusion in interpreting the data. The SDA implicitly assumes one coarse mode and one fine mode, and the AERONET inversion uses the retrieved size distribution to calculate values of the optical depth, effective radius, and effective variance for one coarse mode and one fine mode even if the retrieved size distribution itself shows a multimodal structure. An additional mode of intermediate size would most likely not be completely categorized by either retrieval into one size or the other, and in that case the calculated properties of the coarse and fine modes would both be affected. It is also possible that the adopted methodology will fail to flag some data points where the intermediate mode has a peak radius of a smaller size or that the intermediate mode is present on some data points where it is not significant enough relative to the primary coarse mode for the AERONET inversion to retrieve a distinct peak for it. Such data points would not be flagged in this study. The ultimate objective, though, is to show that the intermediate mode has significantly different radiative properties from the coarse mode typically observed in Saharan and Sahelian dust. It will be demonstrated that the adopted methodology is sufficient and adequate for this purpose.

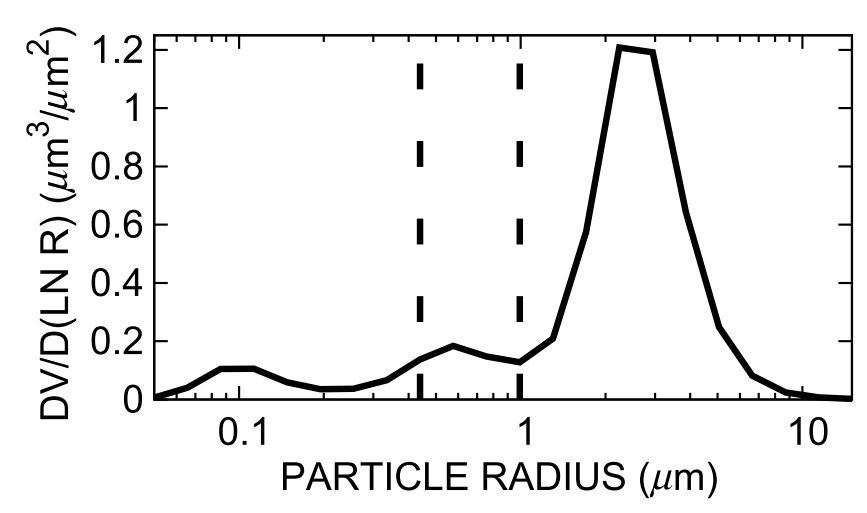

Figure 2. The mean values for the AERONET size distribution retrievals at the Ilorin site on 10 February 2000. The vertical dashed lines denote the values of the particle radius $(0.439 \mu \mathrm{m}$ and $0.992 \mu \mathrm{m})$ between which a peak in the retrieved size distribution must lie for the intermediate mode to be flagged. 


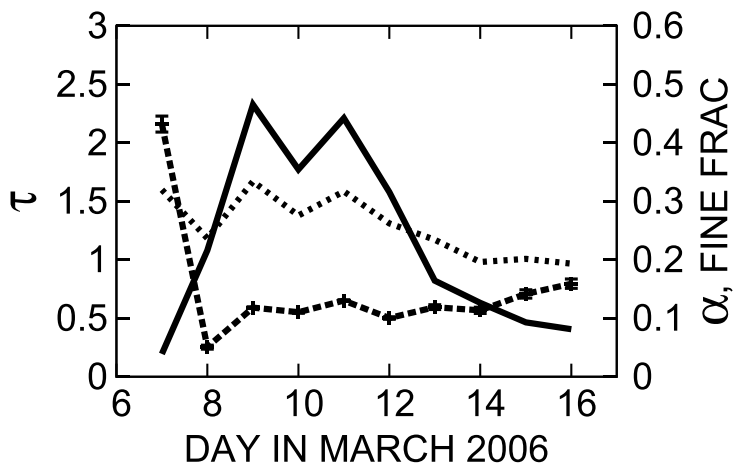

Figure 3. The daily mean values of optical depth at $870 \mathrm{~nm}$ (solid), Ångström exponent between $440 \mathrm{~nm}$ and $870 \mathrm{~nm}$ (dashed), and SDA-retrieved fine mode fraction at $500 \mathrm{~nm}$ (dotted) obtained from AERONET data at the Dakar site between 7 March and 16 March 2006. The error bars denote uncertainties in the mean Ångström exponent.

[19] All 15 sites are examined for the frequency of occurrence of the mode in the AERONET size distribution retrieval. The sites for which the intermediate mode appears in more than $1 \%$ of the data points are examined further, to determine if there are statistically significant differences in the Ångström exponent ( $\alpha$, calculated by a linear regression of the measured optical depths at 440, 500, 675, and $870 \mathrm{~nm})$, SDA-retrieved fine mode fraction at $500 \mathrm{~nm}\left(f_{\mathrm{f}}\right)$, and single-scattering albedo $\left(w_{0}\right)$. For this statistical analysis, individual data points are used as opposed to the daily mean size distributions. While this raises the possibility of giving extra weight in the results to days with a large number of data points, it also allows for diurnal changes in the Angström exponent and single-scattering albedo that correspond to changes in the size distribution to be taken into consideration.

\section{Case Study: The March 2006 Dust Event}

[20] A major Saharan dust event in March 2006 shows how the retrieval of the intermediate mode by the AERONET inversion corresponds to real variations in the wavelength dependence of aerosol optical depth during periods of large dust loading. Figure 3 shows the daily mean values for the optical depth at $870 \mathrm{~nm}$ (solid), the Ångström exponent (dashed), and the SDA-retrieved fine mode fraction at $500 \mathrm{~nm}$ (dotted), obtained from AERONET data at the Dakar site in Senegal between 7 March and 16 March 2006. The uncertainties in the Ångström exponent depicted in the error bars are calculated according to the analysis of Eck et al. [1999]. Variations of this graph have been published before [Derimian et al., 2008; Skonieczny et al., 2011], and both these studies commented on the decrease in the value of $\alpha$ as the dust storm moved in on 8 March. But on 9 and 11 March, the 2 days with the highest value of optical depth during the event, $\alpha$ actually increases relative to the day before by a greater amount than the estimated uncertainties. The variation in the fine mode fraction during this period of time shows a similar pattern to that of the Angström exponent. The mean values of fine mode fraction retrieved on 9 March (33.4\%) and 11 March (31.7\%) are approximately as high, though, as they were before the storm started on 7 March (32.0\%). In fact, the highest fine mode fraction and total optical depth in the plot both occur on 9 March, at the height of the event. So a significant portion of the particles on the days with highest optical depth in this major dust event is small enough to both raise the Ångström exponent and be classified by the SDA algorithm as fine mode particles rather than coarse mode particles.

[21] Similar behavior in the aerosol measurements was observed at a site in Niamey in Niger, located further east and upwind from Dakar. Slingo et al. [2006] reported a sharp increase in the optical depth measured by their MFRSR instrument, from less than 2.0 to over 3.5 between the afternoon of 7 March and the afternoon of 8 March. This increase in optical depth corresponds with a sharp decrease in their retrieved value for the effective radius, from $3.3 \mu \mathrm{m}$ to $1.6 \mu \mathrm{m}$. Thomas and Gautier [2009] compared a dust model with optical depth data from AERONET and another device with infrared wavelengths further in the infrared, in order to make a detailed analysis of the physical properties and chemical composition of the dust in this particular storm. Among other things, they found that a modeled multimodal structure consistent with the results of the AERONET inversion produced the best fit to the data.

[22] The detailed AERONET size distribution retrieval results shown in Figure 4 reflect the evolution of this storm over the site at Dakar. On 7 March, before the dust storm had set in, the maximum value of $\mathrm{d} V / \mathrm{d}(\ln r)$ in the retrieval occurred at a coarse mode radius of $1.30 \mu \mathrm{m}$. A much smaller relative maximum of $\mathrm{d} V / \mathrm{d}(\ln r)$ occurred at a radius of $0.11 \mu \mathrm{m}$, a typical value for fine mode particles. The storm intensified on the following day, and coarse mode particles predictably dominate the size distribution. However, a noticeable portion of the total aerosol volume comes from particles with a radius smaller than $1.0 \mu \mathrm{m}$. On 9 March, much of the total volume increase retrieved by AERONET comes from typical coarse mode particles, as expected. However, the proportion of particles of submicron radius also increases, to the extent that a distinct mode with a peak contribution to the total volume at a radius of $0.58 \mu \mathrm{m}$ can be seen. The value of the particle volume retrieved at this radius is a factor of 2.77 higher on 9 March than it was on 8 March; by contrast, the value of the particle volume retrieved at the peak coarse mode radius of $2.24 \mu \mathrm{m}$ increased between the 2 days by a factor of 1.78 . Note that the optical depth is directly dependent not on total aerosol volume but on particle surface area, so the fractional contribution of this intermediate mode to the total optical depth is greater than its fractional contribution to total aerosol volume.

\section{The Frequency and Characteristics of the Intermediate Mode}

[23] Table 2 shows the number of data points, along with the percentage relative to the total number of data points for which a size distribution is retrieved, that the intermediate mode is and is not flagged for all 15 sites. The results are categorized according to the value of the total aerosol optical depth at $870 \mathrm{~nm}$, with four bins representing $\tau$ values between 0.50 and 0.75 , between 0.75 and 1.00 , between 1.00 and 1.50, and greater than 1.50. The relative frequency of major dust events, both with and without a flagged intermediate mode, varies significantly depending on location. 


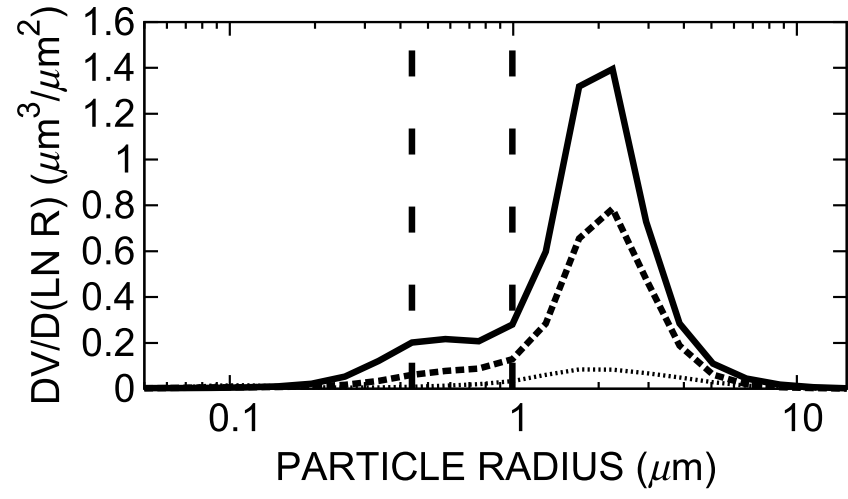

Figure 4. The mean values for the AERONET size distribution retrievals at the Dakar site on 7 March (dotted), 8 March (dashed), and 9 March (solid) 2006. The vertical dashed lines denote the values of the particle radius $(0.439 \mu \mathrm{m}$ and $0.992 \mu \mathrm{m})$ between which a peak in the retrieved size distribution must lie for the intermediate mode to be flagged.

None of the sites north of the Sahel see an optical depth at $870 \mathrm{~nm}$ in excess of 0.5 in more than $10 \%$ of the data points, and of these, only Tamanrasset in the center of the Sahara sees the intermediate mode plus an optical depth above 0.5 in more than $1 \%$ of the data points. Of the remaining sites, Ilorin clearly shows the greatest frequency of both high optical depth events and data points for which the intermediate mode is flagged; $23.2 \%$ of the total data points from Ilorin show an intermediate mode combined with an optical depth in excess of 0.50 . In fact, as optical depth increases, the likelihood of a data point at Ilorin showing the intermediate mode increases as well. For data points at Ilorin where the optical depth exceeds 1.50, the AERONET inversion flags the intermediate mode 104 out of 115 data points. The site with the next highest frequency of occurrence of the intermediate mode is Ouagoudougou, the second most southerly site in the survey. The remaining Sahelian sites are comparable to each other in terms of frequency, although the intermediate mode appears slightly less frequently at Dakar on the Atlantic coast and less frequently still at Capo Verde out on the ocean.

[24] Without investigating further, the relatively high frequency of occurrence of the intermediate mode at the most southern sites in the survey allows for alternate explanations. One is that the intermediate mode is a by-product of biomass burning, which certainly makes a significant contribution to the total aerosol loading at Ilorin [Eck et al., 2010]. Another has to do with the dynamics of dust transport, particularly coming out of the Bodélé Depression. Dust emanating from the Bodélé Depression usually travels to the southwest [Fiedler et al., 2013], so it is not necessarily surprising that Ilorin sees high optical depth events at a greater frequency than the Sahelian sites. Furthermore, dust that tracks westward over the Sahel can mix with dust from additional

Table 2. The Number of Data Points Along With Their Percentage of the Total Data Points in the Set for Which the Intermediate Mode Is and Is Not Flagged at the 15 AERONET Sites Used in This Study ${ }^{\mathrm{a}}$

\begin{tabular}{|c|c|c|c|c|c|c|c|c|}
\hline \multirow[b]{2}{*}{ Intermediate Mode Flagged? } & \multicolumn{2}{|c|}{$0.50 \leq \tau<0.75$} & \multicolumn{2}{|c|}{$0.75 \leq \tau<1.00$} & \multicolumn{2}{|c|}{$1.00 \leq \tau<1.50$} & \multicolumn{2}{|c|}{$\tau \geq 1.50$} \\
\hline & No & Yes & No & Yes & No & Yes & No & Yes \\
\hline Agoufou & $\begin{array}{c}493 \\
(13.0 \%)\end{array}$ & $\begin{array}{c}142 \\
(3.7 \%)\end{array}$ & $\begin{array}{c}241 \\
(6.3 \%)\end{array}$ & $\begin{array}{c}101 \\
(2.7 \%)\end{array}$ & $\begin{array}{c}165 \\
(4.3 \%)\end{array}$ & $\begin{array}{c}94 \\
(2.5 \%)\end{array}$ & $\begin{array}{c}50 \\
(1.3 \%)\end{array}$ & $\begin{array}{c}25 \\
(0.7 \%)\end{array}$ \\
\hline Banizoumbou & $\begin{array}{c}760 \\
(9.8 \%)\end{array}$ & $\begin{array}{c}337 \\
(4.3 \%)\end{array}$ & $\begin{array}{c}307 \\
(4.0 \%)\end{array}$ & $\begin{array}{c}241 \\
(3.1 \%)\end{array}$ & $\begin{array}{c}261 \\
(3.4 \%)\end{array}$ & $\begin{array}{c}199 \\
(2.6 \%)\end{array}$ & $\begin{array}{c}104 \\
(1.3 \%)\end{array}$ & $\begin{array}{c}68 \\
(0.9 \%)\end{array}$ \\
\hline Blida & $\begin{array}{c}43 \\
(1.3 \%)\end{array}$ & $\begin{array}{c}1 \\
(0.0 \%)\end{array}$ & $\begin{array}{c}29 \\
(0.9 \%)\end{array}$ & $\begin{array}{c}2 \\
(0.1 \%)\end{array}$ & $\begin{array}{c}3 \\
(0.1 \%)\end{array}$ & $\begin{array}{c}1 \\
(0.0 \%)\end{array}$ & $\begin{array}{c}0 \\
(0.0 \%)\end{array}$ & $\begin{array}{c}0 \\
(0.0 \%)\end{array}$ \\
\hline Capo Verde & $\begin{array}{c}454 \\
(11.8 \%)\end{array}$ & $\begin{array}{c}41 \\
(1.1 \%)\end{array}$ & $\begin{array}{c}117 \\
(3.1 \%)\end{array}$ & $\begin{array}{c}30 \\
(0.8 \%)\end{array}$ & $\begin{array}{c}57 \\
(1.5 \%)\end{array}$ & $\begin{array}{c}10 \\
(0.3 \%)\end{array}$ & $\begin{array}{c}22 \\
(0.6 \%)\end{array}$ & $\begin{array}{c}1 \\
(0.0 \%)\end{array}$ \\
\hline Dakar & $\begin{array}{c}828 \\
(14.7 \%)\end{array}$ & $\begin{array}{c}96 \\
(1.7 \%)\end{array}$ & $\begin{array}{c}297 \\
(5.3 \%)\end{array}$ & $\begin{array}{c}70 \\
(1.2 \%)\end{array}$ & $\begin{array}{c}154 \\
(2.7 \%)\end{array}$ & $\begin{array}{c}66 \\
(1.2 \%)\end{array}$ & $\begin{array}{c}33 \\
(0.6 \%)\end{array}$ & $\begin{array}{c}18 \\
(0.3 \%)\end{array}$ \\
\hline DMN Maine Soroa & $\begin{array}{c}233 \\
(12.1 \%)\end{array}$ & $\begin{array}{c}47 \\
(2.5 \%)\end{array}$ & $\begin{array}{c}104 \\
(5.4 \%)\end{array}$ & $\begin{array}{c}37 \\
(1.9 \%)\end{array}$ & $\begin{array}{c}56 \\
(2.9 \%)\end{array}$ & $\begin{array}{c}25 \\
(1.3 \%)\end{array}$ & $\begin{array}{c}27 \\
(1.4 \%)\end{array}$ & $\begin{array}{c}13 \\
(0.7 \%)\end{array}$ \\
\hline IER Cinzana & $\begin{array}{c}775 \\
(12.2 \%)\end{array}$ & $\begin{array}{c}250 \\
(3.9 \%)\end{array}$ & $\begin{array}{c}302 \\
(4.8 \%)\end{array}$ & $\begin{array}{c}131 \\
(2.1 \%)\end{array}$ & $\begin{array}{c}178 \\
(2.8 \%)\end{array}$ & $\begin{array}{c}143 \\
(2.3 \%)\end{array}$ & $\begin{array}{c}64 \\
(1.0 \%)\end{array}$ & $\begin{array}{c}40 \\
(0.6 \%)\end{array}$ \\
\hline Ilorin & $\begin{array}{c}550 \\
(20.0 \%)\end{array}$ & $\begin{array}{c}78 \\
(2.8 \%)\end{array}$ & $\begin{array}{c}247 \\
(9.0 \%)\end{array}$ & $\begin{array}{c}169 \\
(6.2 \%)\end{array}$ & $\begin{array}{c}103 \\
(3.8 \%)\end{array}$ & $\begin{array}{c}285 \\
(10.4 \%)\end{array}$ & $\begin{array}{c}11 \\
(0.4 \%)\end{array}$ & $\begin{array}{c}104 \\
(3.8 \%)\end{array}$ \\
\hline Izana & $\begin{array}{c}2 \\
(0.1 \%)\end{array}$ & $\begin{array}{c}2 \\
(0.1 \%)\end{array}$ & $\begin{array}{c}1 \\
(0.1 \%)\end{array}$ & $\begin{array}{c}0 \\
(0.0 \%)\end{array}$ & $\begin{array}{c}0 \\
(0.0 \%)\end{array}$ & $\begin{array}{c}0 \\
(0.0 \%)\end{array}$ & $\begin{array}{c}0 \\
(0.0 \%)\end{array}$ & $\begin{array}{c}0 \\
(0.0 \%)\end{array}$ \\
\hline La Laguna & $\begin{array}{c}38 \\
(4.0 \%)\end{array}$ & $\begin{array}{c}1 \\
(0.1 \%)\end{array}$ & $\begin{array}{c}2 \\
(0.2 \%)\end{array}$ & $\begin{array}{c}0 \\
(0.0 \%)\end{array}$ & $\begin{array}{c}0 \\
(0.0 \%)\end{array}$ & $\begin{array}{c}0 \\
(0.0 \%)\end{array}$ & $\begin{array}{c}0 \\
(0.0 \%)\end{array}$ & $\begin{array}{c}0 \\
(0.0 \%)\end{array}$ \\
\hline Ouagadougou & $\begin{array}{c}225 \\
(7.1 \%)\end{array}$ & $\begin{array}{c}176 \\
(5.6 \%)\end{array}$ & $\begin{array}{c}76 \\
(2.4 \%)\end{array}$ & $\begin{array}{c}154 \\
(4.9 \%)\end{array}$ & $\begin{array}{c}59 \\
(1.9 \%)\end{array}$ & $\begin{array}{c}118 \\
(3.8 \%)\end{array}$ & $\begin{array}{c}19 \\
(0.6 \%)\end{array}$ & $\begin{array}{c}11 \\
(0.4 \%)\end{array}$ \\
\hline Saada & $\begin{array}{c}207 \\
(3.2 \%)\end{array}$ & $\begin{array}{c}7 \\
(0.1 \%)\end{array}$ & $\begin{array}{c}37 \\
(0.6 \%)\end{array}$ & $\begin{array}{c}4 \\
(0.1 \%)\end{array}$ & $\begin{array}{c}7 \\
(0.1 \%)\end{array}$ & $\begin{array}{c}1 \\
(0.0 \%)\end{array}$ & $\begin{array}{c}0 \\
(0.0 \%)\end{array}$ & $\begin{array}{c}0 \\
(0.0 \%)\end{array}$ \\
\hline Santa Cruz Tenerife & $\begin{array}{c}67 \\
(2.3 \%)\end{array}$ & $\begin{array}{c}13 \\
(0.5 \%)\end{array}$ & $\begin{array}{c}20 \\
(0.7 \%)\end{array}$ & $\begin{array}{c}2 \\
(0.1 \%)\end{array}$ & $\begin{array}{c}4 \\
(0.1 \%)\end{array}$ & $\begin{array}{c}2 \\
(0.1 \%)\end{array}$ & $\begin{array}{c}1 \\
(0.0 \%)\end{array}$ & $\begin{array}{c}0 \\
(0.0 \%)\end{array}$ \\
\hline Tamanrasset INM & $\begin{array}{c}69 \\
(4.1 \%)\end{array}$ & $\begin{array}{c}11 \\
(0.7 \%)\end{array}$ & $\begin{array}{c}17 \\
(1.0 \%)\end{array}$ & $\begin{array}{c}7 \\
(0.4 \%)\end{array}$ & $\begin{array}{c}11 \\
(0.7 \%)\end{array}$ & $\begin{array}{c}2 \\
(0.1 \%)\end{array}$ & $\begin{array}{c}3 \\
(0.2 \%)\end{array}$ & $\begin{array}{c}0 \\
(0.0 \%)\end{array}$ \\
\hline Zinder Airport & $\begin{array}{c}80 \\
(6.0 \%)\end{array}$ & $\begin{array}{c}42 \\
(3.1 \%)\end{array}$ & $\begin{array}{c}37 \\
(2.8 \%)\end{array}$ & $\begin{array}{c}28 \\
(2.1 \%)\end{array}$ & $\begin{array}{c}37 \\
(2.8 \%)\end{array}$ & $\begin{array}{c}21 \\
(1.6 \%)\end{array}$ & $\begin{array}{c}4 \\
(0.3 \%)\end{array}$ & $\begin{array}{c}5 \\
(0.4 \%)\end{array}$ \\
\hline
\end{tabular}

${ }^{\mathrm{a}}$ The values are categorized by optical depth at $870 \mathrm{~nm}$. 
GIANELLI ET AL.: EVIDENCE OF A WEAKLY ABSORBING

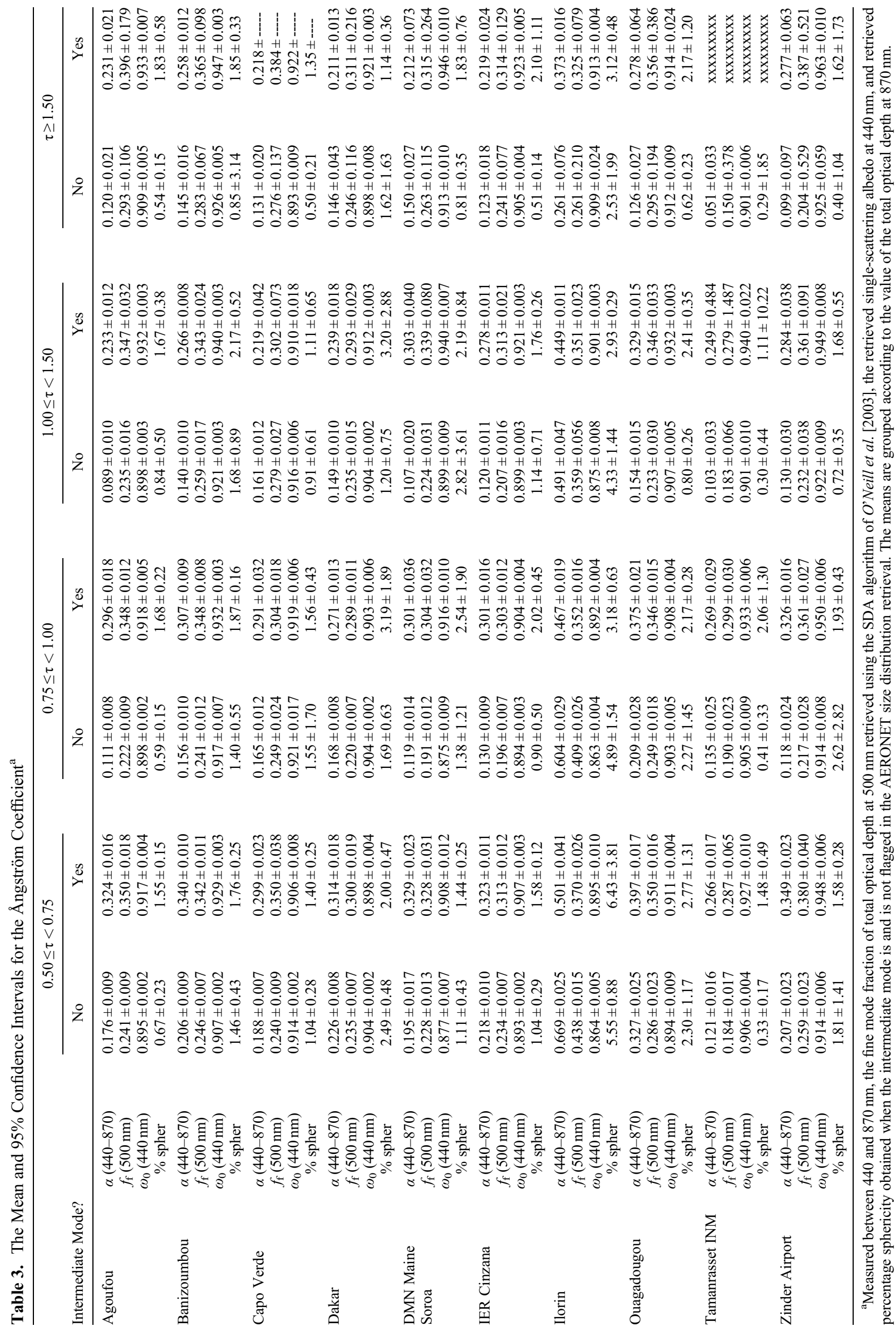


Table 4. The Results of the Linear Regressions of Ångström Exponent and SDA-Retrieved Fine Mode Fraction Versus Aerosol Optical Depth Using Data Points for Which the Intermediate Mode is Flagged ${ }^{\mathrm{a}}$

\begin{tabular}{|c|c|c|c|c|c|c|c|c|}
\hline \multirow[b]{2}{*}{ Site } & \multicolumn{3}{|c|}{$\alpha(440-870)$} & \multicolumn{5}{|c|}{$f_{\mathrm{f}}(500 \mathrm{~nm})$} \\
\hline & $b$ & $m$ & $t^{*} \mathrm{se}$ & sig? & $b$ & $m$ & $\mathrm{t} * \mathrm{se}$ & sig? \\
\hline Agoufou & 0.377 & -0.099 & 0.028 & Yes & 0.329 & 0.025 & 0.010 & Yes \\
\hline Banizoumbou & 0.383 & -0.083 & 0.012 & Yes & 0.331 & 0.016 & 0.004 & Yes \\
\hline Capo Verde & 0.372 & -0.110 & 0.058 & Yes & 0.412 & -0.106 & 0.089 & Yes \\
\hline Dakar & 0.354 & -0.085 & 0.001 & Yes & 0.293 & 0.003 & 0.034 & No \\
\hline DMN Maine Soroa & 0.376 & -0.077 & 0.032 & Yes & 0.319 & 0.003 & 0.005 & No \\
\hline IER Cinzana & 0.373 & -0.082 & 0.030 & Yes & 0.303 & 0.008 & 0.021 & No \\
\hline Ilorin & 0.565 & -0.101 & 0.035 & Yes & 0.385 & -0.031 & 0.014 & Yes \\
\hline Ouagadougou & 0.455 & -0.096 & 0.062 & Yes & 0.348 & 0.000 & 0.067 & No \\
\hline Tamanrasset INM & 0.287 & -0.028 & 4.971 & No & 0.290 & 0.001 & 1.654 & No \\
\hline Zinder Airport & 0.397 & -0.082 & 0.052 & Yes & 0.378 & -0.008 & 0.063 & No \\
\hline
\end{tabular}

${ }^{\text {a }}$ The variable $b$ represents the $y$ intercept, $m$ is the slope, and $t^{*}$ se is the product of the $t$ function at the $95 \%$ confidence interval and the standard error. The statistical significance of the slope relative to a slope of 0 is also presented.

sources [Schepanski et al., 2012], perhaps diluting the signal of the intermediate mode if the mode does originate from the Bodélé Depression. In order to get a clear indication of whether one of these explanations is likely to be correct, more aerosol properties need to be investigated. Biomassburning aerosols have a higher Ångström exponent (due to smaller particle size), a greater fine mode fraction, and a lower single-scattering albedo (due to stronger absorption) than desert dust. They are also more spherical. An examination of how these properties vary with location, optical depth, and the appearance of the intermediate mode in the size distribution retrieval should shed some light on what the intermediate mode really is and what its properties are.

[25] The sites used in Table 3 are determined by whether the total percentage frequency of occurrence of the intermediate mode, over all four optical depth categories, adds up to at least $1.0 \%$. This eliminates all the northern sites from further consideration but leaves in Tamanrasset and Capo Verde along with Ilorin and all the Sahelian sites. The mean values of the Ångström exponent between 470 and $870 \mathrm{~nm}$, the SDA-retrieved fine mode fraction at $500 \mathrm{~nm}$, the single-scattering albedo retrieved at $440 \mathrm{~nm}$, and percentage sphericity are presented for the same four ranges of optical depth at $870 \mathrm{~nm}$ used in Table 2. The range of the $95 \%$ confidence interval of the means, calculated using the Student's $t$ test method, is also presented. This is done to determine if differences in the mean values between when the intermediate mode is and is not flagged are statistically significant over a given range of optical depth.

[26] Given the high frequency of occurrence of the intermediate mode in the retrievals, the mode's increase in significance with increasing optical depth, and the fact that biomass-burning aerosols are known to intermingle with dust in significant proportions, the AERONET site at Ilorin is the most important site in the study and warrants the closest scrutiny. At optical depth values below 1.50, data points with the intermediate mode flagged have a lower Ångström exponent and fine mode fraction than the points where the intermediate mode is not flagged, but these trends reverse at optical depth values above 1.50. The decreased values of $\alpha$ and $f_{\mathrm{f}}$ at optical depths below 1.50 can be explained if the presence of the intermediate mode corresponds to an aerosol loading that consists more purely of dust, while the absence of the intermediate mode corresponds more frequently to a mixture of dust with biomass-burning aerosols. In either case, the smaller biomass-burning particles do not contribute as significantly to the total aerosol loading when the optical depth exceeds 1.50 , so $\alpha$ and $f_{\mathrm{f}}$ increase when the intermediate mode is present.

[27] The Ilorin site in general has lower values of singlescattering albedo and higher values of percentage sphericity than the other sites. These are both consistent with a significant biomass-burning contribution to the total aerosol loading. In all four categories of optical depth, however, the mean single-scattering albedo is significantly higher when the intermediate mode is flagged. In other words, the aerosols absorb less when the intermediate mode is present. If the presence of the intermediate mode had anything to do with biomass burning, the opposite result would be expected. The percentage sphericity is more highly variable than the other quantities examined, and for Ilorin the differences between when the intermediate mode is and is not flagged do not reach statistical significance in any of the optical depth categories.

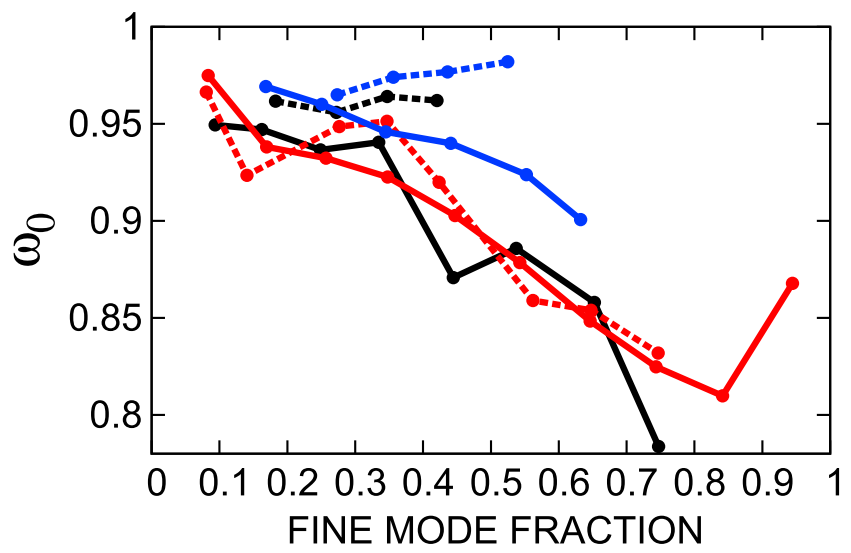

Figure 5. A plot of single-scattering albedo at $675 \mathrm{~nm}$ retrieved using the AERONET inversion algorithm versus the fine mode fraction at $500 \mathrm{~nm}$ retrieved using the SDA algorithm for the DMN Maine Soroa (black), Ilorin (red), and Zinder Airport (blue) sites. The solid lines correspond to the data points for which the intermediate mode is not flagged, while the dashed lines correspond to the data points for which the mode is flagged. 
[28] At every site other than Ilorin, and for each optical depth category, there is a clear difference in the mean Ångström exponents calculated when the intermediate mode is flagged in the AERONET size distribution retrievals than when it is not flagged. The increase in Ångström exponent in the presence of the intermediate mode is universal. With the exception of Capo Verde and Tamanrasset at optical depth values above 1.00 and Maine Soroa at optical depth values above 1.50 , the differences are statistically significant.

[29] It has already been observed in Figure 3 that for dust storms containing the intermediate mode, the SDA can retrieve a value of the fine mode fraction at the height of the storm that is greater than the value retrieved before the storm even hit. An analysis of the mean-retrieved values at multiple sites can show if the increase in fine mode fraction with the presence of the intermediate mode is a general occurrence; if this is indeed the case, the size distribution in dust events cannot be categorically described as a strengthening of just a primary coarse mode. As was the case with the Angström exponents, the increase in fine mode fraction when the intermediate mode is flagged is universal outside of Ilorin. In general, the differences are large enough to be statistically significant. There is enough variation to keep the difference from being statistically significant in a few cases, like large optical depth values at Capo Verde where the sample size is small.

[30] There are some subtle but important differences, however, between how the Ångström exponent and the SDA-retrieved fine mode fraction change with increasing optical depth at a given site. Table 4 shows the results of linear regressions of $\alpha$ (between 440 and $870 \mathrm{~nm}$ ) and $f_{\mathrm{f}}$ (at $500 \mathrm{~nm}$ using the SDA algorithm) versus optical depth at $870 \mathrm{~nm}$ for data points where $t$ exceeds 0.50 and the intermediate mode is flagged. The slope from the regression of $\alpha$ is negative at all 10 sites and statistically significant to the $95 \%$ confidence interval at 9 of the 10. This is an expected result, as dust is composed of larger particles than the background aerosols. If the dust consisted almost entirely of supermicron "coarse mode" particles, the fine mode fraction would decrease with increasing optical depth as well. But as Table 4 shows, 6 of the 10 sites show an increase in fine mode fraction with increasing optical depth. Two sites (Agoufou and Banizombou) show a statistically significant increase in fine mode fraction with increasing optical depth, and two sites (Ilorin and Capo Verde, the two sites for which non-dust particles contribute most significantly to the total aerosol loading) show a statistically significant decrease. This result can be explained if the particles being added as the optical depth increases include particles small enough that the SDA algorithm still identifies them as fine mode particles but large enough relative to background fine mode aerosols to still lower the Ångström exponent.

[31] As a measure of the ability to absorb sunlight, the single-scattering albedo provides some information on the type and chemistry of the aerosol being examined. Included in Table 3 are the mean values of $\omega_{0}$ at $440 \mathrm{~nm}$ retrieved by the AERONET inversion. At every site except Capo Verde, the mean value of $\omega_{0}$ at optical depths above 1.00 is greater when the intermediate mode is flagged than when it is not. For optical depth values below 1.00, the mean single-scattering albedo is less when the intermediate is flagged only at Capo Verde and Dakar, and in neither case is the difference statistically significant. At DMN Maine Soroa and Zinder Airport, the sites closest to the Bodélé Depression, the mean value of $\omega_{0}$ at $440 \mathrm{~nm}$ when the intermediate mode is flagged becomes exceptionally large as the optical depth increases (0.946 and 0.963 , respectively, at optical depths greater than 1.50). This strongly suggests that the particles in the intermediate mode do not absorb sunlight with the same efficiency that regular desert dust does.

[32] Figure 5, which plots the single-scattering albedo retrieved at $675 \mathrm{~nm}$ by the AERONET inversion versus the fine mode fraction retrieved at $500 \mathrm{~nm}$ using the SDA algorithm at the DMN Maine Soroa, Ilorin, and Zinder Airport sites, further illustrates the absorption differences between the intermediate mode and ordinary desert dust. When the size distribution retrieval does not show an intermediate mode, $\omega_{0}$ generally decreases with fine mode fraction. This is consistent with a fine mode containing a significant portion of strongly absorbing biomass-burning aerosols. When the intermediate mode is present, however, there is an increase in $\omega_{0}$ at all three sites as the fine mode fraction increases above 0.3 . At Ilorin, the increase is only temporary; for fine mode fractions greater than 0.5 , biomass-burning aerosols dominate and the effect of the intermediate mode vanishes. At Maine Soroa and Zinder Airport, the difference in $\omega_{0}$ between data points with a retrieved intermediate mode and those without it increases with increasing fine mode fraction. As these sites do not have the same degree of overlap between biomass burning and dust observed at Ilorin, the fine mode fraction almost never exceeds 0.5 when the intermediate mode is present.

[33] The retrieved values of the percent sphericities show a pattern, but the results are less conclusive than with the other retrieved quantities. On a general level, the most southerly site (Ilorin) has the highest amount of spherical particles, due to the contribution of fine biomass-burning aerosols. Outside of Ilorin, the percentage sphericity is usually higher when the intermediate mode is flagged, but the difference is large enough to be statistically significant only in a few cases. Dakar, DMN Maine Soroa, Ouagadougou, and Zinder Airport have size bins where the mean-retrieved percent sphericity is lower when the intermediate mode is flagged, but in none of these cases the difference is statistically significant. The results are complicated further because the retrieval of percent sphericity is not sensitive to the shape particles with an Ångström exponent greater than 1.0 [Dubovik et al., 2006]. So the higher values of percent sphericity could stem from intermediate modes being less spherical than typical coarse mode dust, or they could stem from the particles simply being smaller.

\section{Discussion}

[34] By themselves, neither the results of the AERONET size distribution retrieval prove that the intermediate aerosol mode observed in Saharan dust events does in fact exist and is an artifact of the AERONET inversion nor do the results quantitatively establish the size of the intermediate mode. But AERONET optical depth measurements do show a consistent, distinct difference in the Ångström exponent when the intermediate mode is and is not seen. Table 3 shows, at every site where the intermediate mode is present with a noticeable frequency, a statistically significant increase in the 
Ångström exponent when the intermediate mode has its own peak in the size distribution retrieval. The results from the SDA algorithm of O'Neill et al. [2003] likewise show an increase in the relative contribution of smaller particles to the total optical depth, but there are differences in the behavior of the Ångström exponent and the SDA-derived fine mode fraction. Both of which are obtained using only direct beam data that can be readily explained if the size distributions retrieved by the AERONET inversion are taken at face value. Linear regressions of the Ångström exponent with optical depth when the intermediate mode is flagged have significantly negative slopes at most of the examined sites, but the fine mode fraction shows no conclusive evidence of a similar trend. Furthermore, the dust event of March 2006 shows that sometimes the Ångström exponent actually increases with optical depth during specific dust storms, and the SDA-retrieved fine mode fraction at the height of the storm can even exceed its value before the storm. Substantial evidence exists in the AERONET direct beam data, therefore, that particles smaller than those in the predominant coarse mode but larger than typical fine mode particles are present in significant amounts in some major Saharan dust events.

[35] In addition, the frequency of occurrence of the intermediate mode follows a physically plausible pattern. The intermediate mode is found with the greatest frequency at Ilorin, the site most frequently downwind of the Bodélé Depression. Sites more directly west of the Bodélé Depression also see the mode, with diminishing frequency at more remote sites like Capo Verde and Dakar. Of the sites located further north than the Bodélé, only Tamanrasset in the central Sahara sees the mode with any frequency. So the presence of the intermediate mode in the AERONET inversions depends heavily on location, in a way that is consistent with prevailing wind patterns. The Version 1.0 AERONET inversion could produce spurious additional coarse modes when applied to dust [Osborne et al., 2008], but the Version 2.0 inversion employed here does not appear to suffer from the same issues. And if the example presented in the Osborne et al. study was characteristic of the spurious coarse mode, it had a larger particle size than the primary coarse mode, not a smaller size.

[36] While more airborne studies at the right places and times are needed to clearly define the size and the absorptive properties of the intermediate mode, the limited number of existing studies does show some agreement between airborne measurements and the AERONET inversions. For example, a recent airborne study by Chen et al. [2011] using the Cape Verde island chain as its base determined that the size distribution of their collected Saharan dust particles could be parameterized using three lognormal distributions corresponding to a coarse mode, a fine mode, and an intermediate mode. Using the median parameters of these distributions, the values of the effective radius of each mode are calculated to be $0.13,0.46$, and $1.20 \mu \mathrm{m}$. The first two values are consistent with what is retrieved by AERONET, and the small value of the third can be explained by limitations in the particle sampler, which had a cutoff diameter of $4 \mu \mathrm{m}$. Similar studies based in locations like Ilorin or the regions of the Sahel closer to the Bodélé Depression would be better situated to study the intermediate mode, however.

[37] Osborne et al. [2008] conducted a direct comparison between size distributions obtained from airborne sampling and those retrieved from AERONET data at the Banizoumbou site. The comparisons presented in Figure 10 of that paper suggest that the AERONET inversion overestimates the contribution of submicron particles to the total aerosol volume, but the discrepancies may be a result of the normalization of the data. In addition, the methodology of this study would flag the intermediate mode in the airborne measurements presented in the lower graph of Figure 10. Johnson and Osborne [2011] also make a direct comparison of volume size distributions obtained from airborne data and AERONET data from Banizoumbou and Dakar. The respective means agree very well in general, although the aircraft measurements give a coarse mode peak at a slightly smaller particle size than the AERONET retrievals. In addition, the mean normalized values of $\mathrm{d} V / \mathrm{d}(\ln r)$ measured with the airborne particle sampler at approximate radius values of $0.55 \mu \mathrm{m}$ and $0.9 \mu \mathrm{m}$ are nearly equal, which is consistent with an at least occasional presence of an intermediate mode.

[38] Airborne studies can be combined with AERONET and satellite data to show how dust properties, including the size distribution, evolve over time as the cloud spreads both horizontally and vertically. Examining the vertical distribution of dust clouds shown to contain the intermediate mode, particularly with regards to how the size distribution changes with height, can provide further insight into how this mode propagates spatially and temporally.

[39] Not only does the source of the intermediate mode need to be identified but also what it is about the mode's basic nature that distinguishes it from normal desert dust should be investigated as well. For example, a connection may exist between the intermediate mode and the submicron dust aerosols postulated by Gomes et al. [1990] to be formed from sandblasting. If the Bodélé Depression is indeed the source of the aerosols, then the unusual diatomite sediment found there [Bristow et al., 2009; Todd et al., 2007] may have something to do with the intermediate mode. Any establishment of the source and nature of the intermediate mode would also require an explanation for why the mode is more significant in some major dust storms than in others and why the mode's ability to absorb sunlight is weaker than that of normal desert dust.

[40] The work done for this study continues with an examination of the climatology of the intermediate mode at the different AERONET sites, along with an attempt to explain the differences in retrieval results between the sites. While the high frequency of the mode's occurrence in dust events over the Ilorin site suggests the Bodélé Depression in Chad as a possible source, this still needs to be determined more conclusively. This can be done by combining the AERONET data used in this study with satellite data and back trajectory analysis.

\section{Summary and Conclusions}

[41] In order to precisely determine the effect of desert dust on solar radiation and human health, it is first necessary to quantify the aerosol size distribution. This is a daunting task, as only AERONET makes routine retrievals of the size distribution in significant detail, and the means to validate these retrievals are often lacking. Sometimes, when applied to dust events in the Sahara or Sahel, the AERONET inversion retrieves a more complicated size distribution than the 
frequently assumed coarse/fine bimodality. This happens often enough, and with some characteristics that are consistent over different locations, to justify examining the data further in order to better clarify what is actually happening.

[42] In particular, a significant number of size distribution retrievals taken during dust events show an aerosol mode of an intermediate size between what is generally defined as the coarse mode and the fine mode. The mode is present in retrievals taken during a number of dust events over multiple AERONET sites. Included among these events is the major dust storm of March 2006, where the Ångström exponent observed over Dakar counterintuitively increased with increasing optical depth on the days when the intermediate mode was observed, and the fine mode fraction retrieved using the SDA algorithm at the height of the storm exceeded the value retrieved before the storm began.

[43] A general survey of AERONET measurements at sites in Africa and on the Atlantic shows a number of differences between dust events where the intermediate mode is and is not flagged as being present. The frequency of major dust events in general and events which feature the intermediate mode in particular is most common among the sites examined in this study at Ilorin, the site most frequently downwind of the Bodéle Depression. The intermediate mode is observed less frequently over the Sahel, and the frequency decreases further moving out over the Atlantic from Dakar to Cape Verde. Excepting Ilorin, where biomass-burning aerosols contribute significantly to aerosol loadings when the optical depth is less than 1.50, the Angström exponent is consistently and significantly higher when the intermediate mode is flagged in the data. The SDA retrievals of O'Neill et al. [2003] likewise show an increase in the relative concentration of smaller particles, but the retrieved fine mode fraction does not show the same decreasing trend with increasing optical depth when the intermediate mode is flagged that the Ångström exponent does. The single-scattering albedo is also consistently and significantly larger when the intermediate mode is flagged, suggesting that the particles in the intermediate mode do not absorb sunlight as efficiently as regular dust particles.

[44] The combination of the calculations of the Angström exponent and SDA-derived retrievals of the fine mode fraction, both of which require only optical depth measurements, can be readily explained if the intermediate mode observed in AERONET inversions using measurements of scattered radiation indeed reflects physical reality. Also, the frequency of occurrence of the intermediate mode in the size distribution retrievals follows a pattern that appears to be consistent with prevailing wind patterns. This consistency can be tested further by examining the climatology of the intermediate mode in more detail on a site-to-site basis. But to establish the existence and properties of the intermediate mode more completely, the results of the AERONET inversions will need to be validated using airborne data at locations and times where the intermediate mode is commonly observed.

[45] Acknowledgments. The research for this project was funded through the NASA cooperative agreement NNX07AP74A. The authors are very thankful to AERONET and PHOTONS for establishing and maintaining the sites used in this work. The sun photometers are operated by Service d'Observation PHOTONS from CNRS-Lille 1 University. The principal investigators at the AERONET sites are Phillipe Goloub (Agoufou, Izana), Didier Tanré (Banizoumbou, Capo Verde, Dakar, DMN Maine Soroa, Ouagadougou), Brent Holben (Blida), Jean Louis Rajot
(DMN Maine Soroa, Zinder Airport), Bernadette Chatenet (IER Cinzana, Zinder Airport), Rachel T. Pinker (Ilorin), Emilio Cuevas-Agullo (Izana, Santa Cruz Tenerife, Tamanrasset IMN), Francisco Javier Expssito Gonzalez (La Laguna), Bernard Mougenot (Saada), Benoit Duchemin (Saada), and Mohamed Mimouni (Tamanrasset IMN). The site managers are Franck Timouk (Agoufou), Bernadette Chatenet (Banizoumbou, Capo Verde, DMN Maine Soroa, IER Cinzana), Menouer Boughedaoui (Blida), Aboubacry Diallo (Dakar), Modibo Coulibaly (IER Cinzana), Issa Kone (IER Cinzana), Clement Akoshile (Ilorin), Ramon Ramos (Izana, Santa Cruz Tenerife, Tamanrasset IMN), Luc Blarel (Izana), Juan Pedro Diaz Gonzalez (La Laguna), Zouhair Benkhaldoun (Saada), Aziza Bounhir (Saada), Lahouari Zeudmi-Sahraoui (Tamanrasset IMN), Moussa Abdou Saley (Zinder Airport), and Moussa Mahamadou (Zinder Airport). The authors would also like to thank the reviewers, whose constructive criticism substantially improved the final manuscript.

\section{References}

Anenberg, S. C., L. W. Horowitz, D. Q. Tong, and J. J. West (2010), An estimate of the global burden of anthropogenic ozone and fine particulate matter on premature human mortality using atmospheric modeling, Environ. Health Perspect., 118, 1189-1195, doi:10.1289/ehp.0901220.

Bristow, C. S., N. Drake, and S. Armitage (2009), Deflation in the dustiest place on Earth: The Bodélé Depression, Chad, Geomorphology, 105, 50-58.

Chen, G., et al. (2011), Observations of Saharan dust microphysical and optical properties from the Eastern Atlantic during NAMMA airborne field campaign, Atmos. Chem. Phys., 11, 723-740.

Cohen, A. J., et al. (2005), The global burden of disease due to outdoor air pollution, J. Toxicol. Environ. Health Part A, 68, 1301-1307.

De Longueville, F., Y.-C. Hountondji, S. Henry, and P. Ozer (2010), What do we know about effects of desert dust on air quality and human health in West Africa compared to other regions?, Sci. Total Environ., 409, 1-8. Derimian, Y., J.-F. Léon, O. Dubovik, I. Chiapello, D. Tanré, A. Sinyuk, F. Auriol, T. Podvin, G. Brogniez, and B. N. Holben (2008), Radiative properties of aerosol mixture observed during the dry season 2006 over M'Bour, Senegal (African Monsoon Multidisciplinary Analysis campaign), J. Geophys. Res., 113, D00C09, doi:10.1029/2008JD009904.

Deroubaix, A., N. Martiny, I. Chiapello, and B. Marticorena (2013), Suitability of OMI aerosol index to reflect mineral dust surface conditions: Preliminary application for studying the link with meningitis epidemics in the Sahel, Remote Sens. Environ., 133, 116-127.

Dubovik, O., and M. D. King (2000), A flexible inversion algorithm for retrieval of aerosol optical properties from Sun and sky radiance measurements, J. Geophys. Res., 105, 20,673-20,696.

Dubovik, O., et al. (2006), Application of spheroid models to account for aerosol particle nonsphericity in remote sensing of desert dust, J. Geophys. Res., 111, D11208, doi:10.1029/2005JD006619.

Dusek, U., et al. (2006), Size matters more than chemistry for cloud-nucleating ability of aerosol particles, Science, 312, 1375-1378.

Eck, T. F., B. N. Holben, J. S. Reid, O. Dubovik, A. Smirnov, N. T. O’Neill, I. Slutsker, and S. Kinne (1999), Wavelength dependence of the optical depth of biomass burning, urban, and desert dust aerosols, J. Geophys. Res., 104, 31,333-31,349.

Eck, T. F., et al. (2010), Climatological aspects of the optical properties of fine/coarse mode aerosol mixtures, J. Geophys. Res., 115, D19205, doi:10.1029/2010JD014002.

Fiedler, S., K. Schepanski, B. Heinold, P. Knippertz, and I. Tegen (2013), Climatology of nocturnal low-level jets over North Africa and implications for modeling mineral dust emission, J. Geophys. Res. Atmospheres, $118,6100-6121$, doi:10.1002/jgrd.50394.

Gomes, L., G. Bergametti, G. Coudé-Goussen, and P. Rognon (1990), Submicron desert dusts: A sandblasting process, J. Geophys. Res., 95, $13,927-13,935$

Hansen, J. E., and L. D. Travis (1974), Light scattering in planetary atmospheres, Space Sci. Rev., 16, 527-610.

Harrison, L., J. Michalsky, and J. Berndt (1994), Automated multifilter rotating shadow-band radiometer: An instrument for optical depth and radiation measurements, Appl. Opt., 33, 5118-5125.

Holben, B. N., T. F. Eck, and R. S. Fraser (1991), Temporal and spatial variability of aerosol optical depth in the Sahel region in relation to vegetation remote sensing, Int. J. Remote Sens., 12, 1147-1163.

Holben, B. N., et al. (1998), AERONET - A federated instrument network and data archive for aerosol characterization, Remote Sens. Environ., 66, 1-16.

Johnson, B. T., and S. R. Osborne (2011), Physical and optical properties of mineral dust aerosol measured by aircraft during the GERBILS campaign, Q. J. Roy. Meteorol. Soc., 137, 1117-1130.

Kassianov, E. I., J. C. Barnard, and T. P. Ackerman (2005), Retrieval of aerosol microphysical properties using surface Multifilter Rotating Shadowband Radiometer (MFRSR) data: Modeling and observations, J. Geophys. Res., 110, D09201, doi:10.1029/2004JD005337. 


\section{GIANELLI ET AL.: EVIDENCE OF A WEAKLY ABSORBING}

Kaufman, Y. J., A. Setzer, D. Ward, D. Tanre, B. N. Holben, P. Menzel, M. C. Pereira, and R. Rasmussen (1992), Biomass Burning Airborne and Spaceborne Experiment in the Amazonas (BASE-A), J. Geophys. Res., 97(D13), 14,581-14,599, doi:10.1029/92JD00275.

Martiny, N., and I. Chiapello (2013), Assessments for the impact of mineral dust on the meningitis incidence in West Africa, Atmos. Environ., 70, 245-253.

O'Neill, N. T., O. Dubovik, and T. F. Eck (2001), Modified Ångström exponent for the characterization of submicrometer aerosols, Appl. Opt., 40, 2368-2375.

O’Neill, N. T., T. F. Eck, A. Smirnov, B. N. Holben, and S. Thulasiraman (2003), Spectral discrimination of coarse and fine mode optical depth, J. Geophys. Res., 108(D17), 4559, doi:10.1029/2002JD002975.

Osborne, S. R., B. T. Johnson, J. M. Haywood, A. J. Baran, M. A. J. Harrison, and C. L. McConnell (2008), Physical and optical properties of mineral dust aerosol during the Dust and Biomass-burning Experiment, J. Geophys. Res., 113, D00C03, doi:10.1029/2007JD009551.

Reid, J. S., E. A. Reid, A. Walker, S. Piketh, S. Cliff, A. Al Mandoos, S.-C. Tsay, and T. F. Eck (2008), Dynamics of southwest Asian dust particle size characteristics with implications for global dust research, J. Geophys. Res., 113, D14212, doi:10.1029/2007JD009752.

Ridley, D. A., C. L. Heald, and B. Ford (2012), North African dust export and deposition: A satellite and model perspective, J. Geophys. Res., 117, D02202, doi:10.1029/2011JD016794.

Romakkaniemi, S., A. Arola, H. Kokkola, W. Birmili, T. Tuch, V.-M. Kerminen, P. Räisänen, J. N. Smith, H. Korhonen, and A. Laaksonen (2012), Effect of aerosol size distribution changes on $\mathrm{AOD}, \mathrm{CCN}$, and cloud droplet concentration: Case studies from Erfurt and Melpitz, Germany, J. Geophys. Res., 117, D07202, doi:10.1029/2011JD017091.

Schepanski, K., I. Tegen, and A. Macke (2012), Comparison of satellite based observations of Saharan dust source areas, Remote Sens. Environ. 123, 90-97.

Schuster, G. L., O. Dubovik, and B. N. Holben (2006), Angstrom exponent and bimodal aerosol size distributions, J. Geophys. Res., 111, D07207, doi:10.1029/2005JD006328.

Skonieczny, C., et al. (2011), The 7-13 March 2006 major Saharan outbreak: Multiproxy characterization of mineral dust deposited on the West African margin, J. Geophys. Res., 116, D18210, doi:10.1029/2011JD016173.

Slingo, A., et al. (2006), Observations of the impact of a major Saharan dust storm on the atmospheric radiation balance, Geophys. Res. Lett., 33, L24817, doi:10.1029/2006GL027869.

Thomas, M., and C. Gautier (2009), Investigations of the March 2006 African dust storm using ground-based column-integrated high spectral resolution infrared $(8-13 \mathrm{~mm})$ and visible aerosol optical thickness measurements: 2. Mineral aerosol mixture analyses, J. Geophys. Res., 114, D14209, doi:10.1029/2008JD010931

Todd, M. C., R. Washington, J. V. Martins, O. Dubovik, G. Lizcano, S. M'Bainayel, and S. Engelstaedter (2007), Mineral dust emission from the Bodélé Depression, northern Chad, during BoDEx 2005, J. Geophys. Res., 112, D06207, doi:10.1029/2006JD007170. 